\title{
Effect of Bridge-Pier Differential Settlement on the Dynamic Response of a High-Speed Railway Train-Track-Bridge System
}

\author{
Xiaohui Zhang, Yao Shan, and Xinwen Yang \\ Key Laboratory of Road and Traffic Engineering of the Ministry of Education, Tongji University, Shanghai 201804, China \\ Correspondence should be addressed to Xiaohui Zhang; 1988xiaohui@tongji.edu.cn
}

Received 20 June 2017; Accepted 15 August 2017; Published 24 September 2017

Academic Editor: Dane Quinn

Copyright (c) 2017 Xiaohui Zhang et al. This is an open access article distributed under the Creative Commons Attribution License, which permits unrestricted use, distribution, and reproduction in any medium, provided the original work is properly cited.

A model based on the theory of train-track-bridge coupling dynamics is built in the article to investigate how high-speed railway bridge pier differential settlement can affect various railway performance-related criteria. The performance of the model compares favorably with that of a 3D finite element model and train-track-bridge numerical model. The analysis of the study demonstrates that all the dynamic response for a span of $24 \mathrm{~m}$ is slightly larger than that for a span of $32 \mathrm{~m}$. The wheel unloading rate increases with pier differential settlement for all of the calculation conditions considered, and its maximum value of 0.695 is well below the allowable limit. Meanwhile, the vertical acceleration increases with pier differential settlement and train speed, respectively, and the values for a pier differential settlement of $10 \mathrm{~mm}$ and speed of $350 \mathrm{~km} / \mathrm{h}$ exceed the maximum allowable limit stipulated in the Chinese standards. On this basis, a speed limit for the exceeding pier differential settlement is determined for comfort consideration. Fasteners that had an initial tensile force due to pier differential settlement experience both compressive and tensile forces as the train passes through and are likely to have a lower service life than those which solely experience compressive forces.

\section{Introduction}

China has embarked on an extensive program of building high-speed railway lines. The length of its high-speed operating network of approximately $17,000 \mathrm{~km}$ through July 2015 accounts for approximately $60 \%$ of the world's total. The majority of these lines have been built on bridges (i.e., $80.5 \%$ [1] for the Beijing-Shanghai High-Speed Railway with a total length of approximately $1,318 \mathrm{~km}$ ). This approach is employed because bridges, compared to other structures, can provide a more stable foundation for the railway track. However, a major issue for railway bridges concerns the allowable amount of differential settlement between adjacent bridge piers as this directly affect running safety, passenger comfort, and potential damage to structural components. Bridge-pier differential settlement can occur in railway lines. This is particularly true in those built in soft soil areas due to changes in pier support condition and nearby construction.
Consequently, a bridge-pier differential settlement control standard for nonballasted railway has been developed in China [2]. Especially for high-speed railway lines, the differential settlement between two adjacent piers must be limited to $5 \mathrm{~mm}$ [3].

Nevertheless, excessive bridge-pier differential settlement has not been completely avoided, and, for example, such a problem has occurred at the Wangyu River Bridge (see Figure 1) of the Shanghai-Nanjing Intercity High-Speed Railway, which is the busiest high-speed railway line with a design speed of $350 \mathrm{~km} / \mathrm{h}$. The maximum differential settlement between two adjacent piers (with a spacing of $32 \mathrm{~m}$ ) is approximately $10 \mathrm{~mm}$, thus leading to an abnormal response of the train when passing through this area. As a consequence, the train speed must be strictly limited, and onerous maintenance for these piers must be done in the extremely short time allowed for this work. This greatly affects the transportation efficiency. The value of the speed limit 


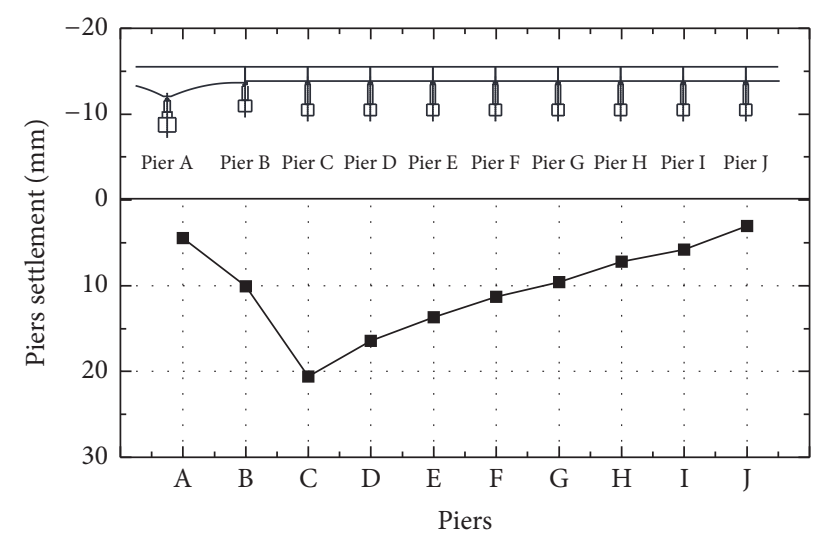

FIGURE 1: Excessive bridge-pier differential settlement.

is not determined in the standard, although it is directly related to running safety and passenger comfort. Therefore, it is necessary to study the effect of pier differential settlement on the dynamic response of the system.

A number of authors have undertaken studies to investigate the vehicle-bridge interaction problem. Yang and Lin [4] presented a procedure based on the dynamic condensation method for simulating the dynamic response of general vehicle-bridge systems. To improve Yang's model, Azimi et al. [5] developed a modified two-dimensional VBI element for vehicles experiencing sudden deceleration with sliding. To improve the accuracy of train-track-bridge interaction studies, Ziyaeifar [6] introduced a technique based on using the Maxwell model for representing the suspension mechanism of train systems. Zhai et al. [8] and Zhang et al. [9] also presented frameworks to investigate the high-speed traintrack-bridge dynamic interactions. All models listed above have laid a solid foundation for studying the pier differential settlement on the vehicle-track-bridge system.

On the basis of vehicle-bridge coupled models, some researchers have focused on the effect of bridge-pier differential settlement on different performance criterion. For example, Invernizzi et al. [7] built a laboratory model on a $1: 2$ scale of a two-span masonry arch bridge to investigate the effect of the central pile settlement, and the main research was focused on the bridge structure. From the point of view of track and pier, Hu et al. [10] utilized a three-dimensional finite element model (FEM) to analyze the effect of pier differential settlement on related structures and suggested a settlement limit value depending on track deformation and pier forces. On the basis of a mechanism analysis of rail deformation along with pier settlement, Chen et al. [11, 12] obtained analytic expressions of the mapping relationship between pier settlement and rail deformation in the unit slab track system and longitudinally connected slab track system. However, they only focused on the static response due to the pier differential settlement. Yau investigated the dynamic response of a maglev vehicle [13] and a high-speed train [14] traveling over a multispan bridge undergoing ground support settlement. Utilizing a numerical dynamic model of the train-track-bridge system $[15,16]$ and assuming that the rail deformation caused by pier differential settlement was entirely translated into track surface irregularities, Wang et al. [17] related pier differential settlement with running safety and passenger comfort. By means of a similar method, Cao et al. [18] considered the rail deformation induced by engineering behaviors near the bridge piers using a threedimensional FEM and studied the effect of pier differential settlement on the dynamic response of the train-track-bridge system with the same assumption.

However, the static response of the track-bridge system due to the pier differential settlement is in fact a process of rebalancing the track structures and bridge beams according to the pier differential settlement under the effect of structure self-weight. Because the bridge beams (especially a simply supported beam bridge) are discontinuous in the longitudinal direction at piers, but the rail is continuous, the rail deformation differs from the bridge beam deformation at certain positions (see Figure 2), leading to initial forces on fasteners before the train arrives. Consequently, the assumption made by Wang, Song, and Cao regarding rail deformation and track surface irregularities (regardless of the initial forces on fasteners due to the pier differential settlement) results in track support conditions which differ significantly from those found in practice. Thus, the modeling of pier differential settlement in this manner results in an incorrect dynamic response of related components (e.g., fasteners) and can therefore lead to incorrect estimates of the allowable differential settlement.

To address the issues, which are apparent in the identified existing studies and to simulate the static and dynamic response of the system due to the pier differential settlement in a more proper way, a model based on the theory of vehicle-track coupling dynamics [19], which considers the system self-weight, was developed to investigate the effect of differential settlement value, driving speed, and bridge span on the static and dynamic response of the system. To determine the allowable settlement, limiting performance criteria which consider stability, safety, and potential damage to the components were considered.

\section{Train-Track-Bridge Coupled Model}

2.1. Calculation Model. The train-track-bridge vertical coupled model includes the dynamic model of vehicle, rail, track slab, concrete base, bridge, and the interaction between these subsystems (see Figure 3). The most important feature of the coupled model is that it can consider the effect of the self-weight of related structures, which makes it possible to calculate the static and dynamic response of the system affected by a pier differential settlement.

The vehicle subsystem consists of one vehicle body, two bogies, and four wheel sets and has 10 degrees of freedom (DOFs) as shown in Figure 4.

Based on multirigid system dynamics theory, the vehicle dynamics model is written as

$$
\left[\mathbf{M}_{\mathbf{v}}\right]\left\{A_{v}\right\}+\left[\mathbf{C}_{\mathbf{v}}\right]\left\{V_{v}\right\}+\left[\mathbf{K}_{\mathbf{v}}\right]\left\{X_{v}\right\}=\left\{F_{v}\right\},
$$




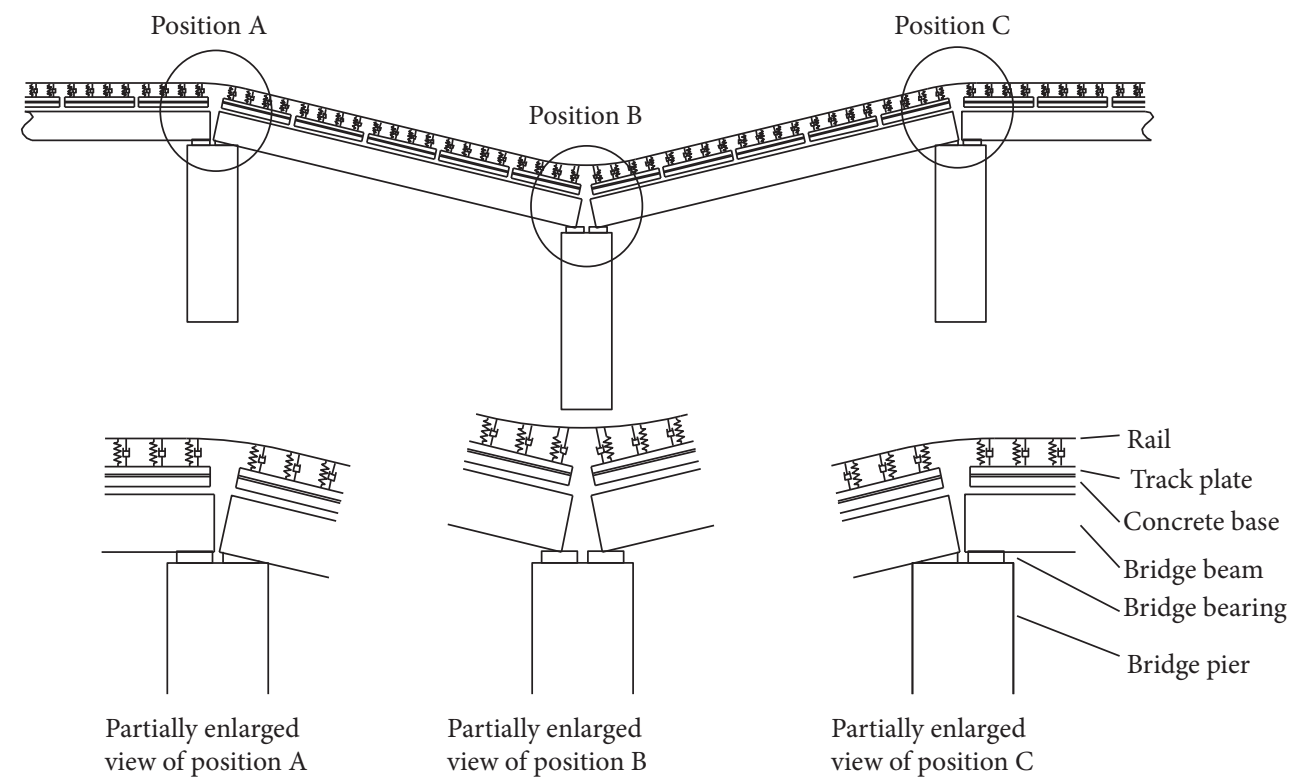

FIGURE 2: Certain positions where the rail deformation differs from the bridge beam deformation.

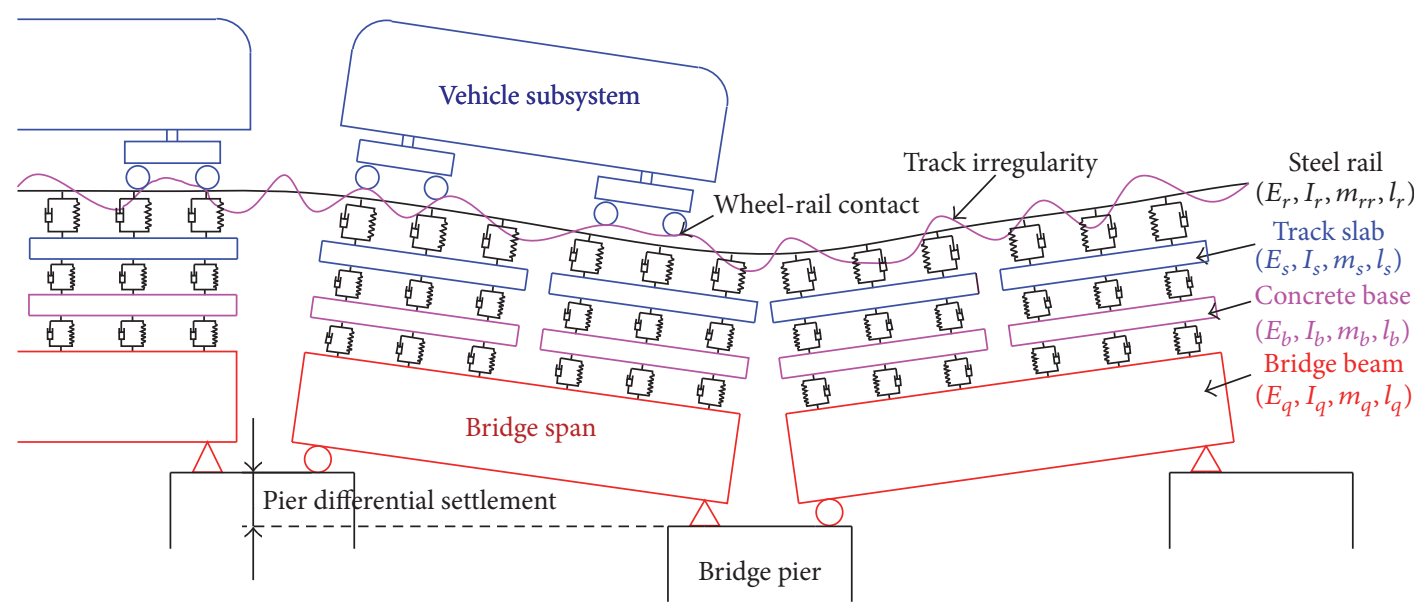

FIGURE 3: Dynamic model of coupled train-track-bridge system.

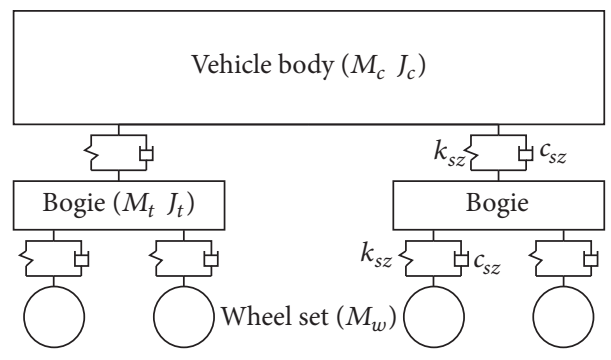

FIgURE 4: Vehicle subsystem model. 
of which the structural matrices of $\left[\mathbf{M}_{\mathbf{v}}\right],\left[\mathbf{K}_{\mathbf{v}}\right],\left[\mathbf{C}_{\mathbf{v}}\right]$, and the force vector $\left\{F_{v}\right\}$ can be given as follows:

$$
\begin{aligned}
& {\left[\mathbf{M}_{\mathbf{v}}\right]=\operatorname{diag}\left[\begin{array}{llllllllll}
M_{c} & J_{c} & M_{t} & J_{t} & M_{t} & J_{t} & M_{w} & M_{w} & M_{w} & M_{w}
\end{array}\right]}
\end{aligned}
$$

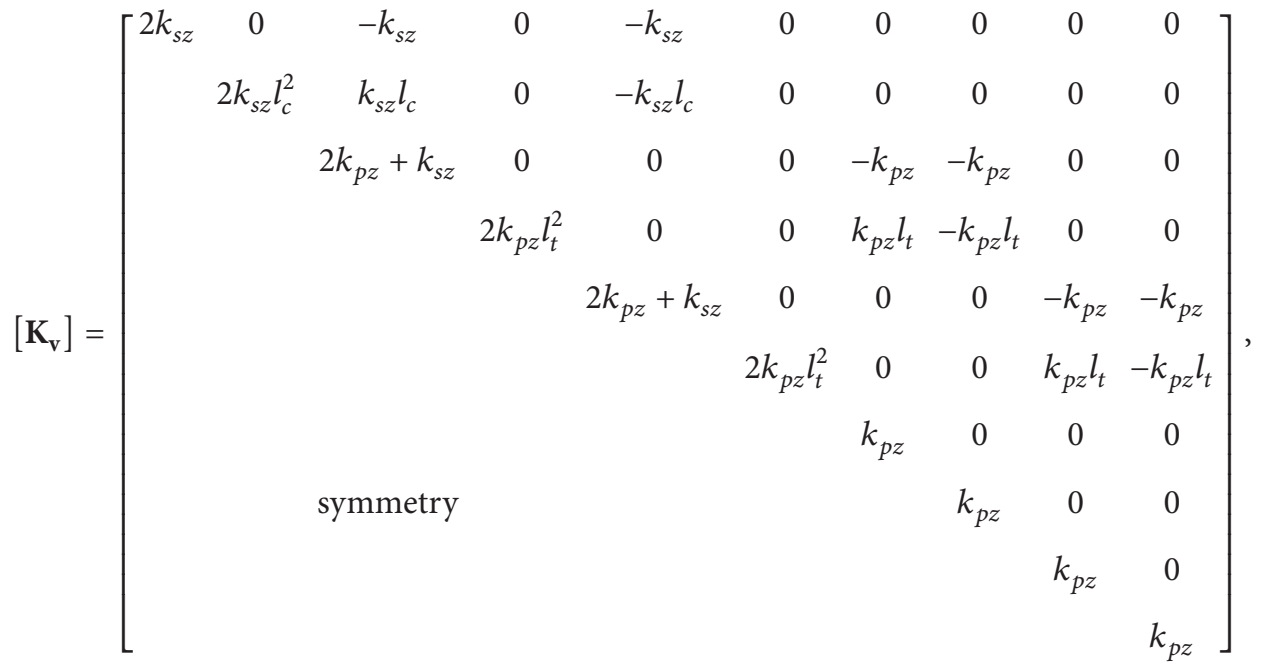

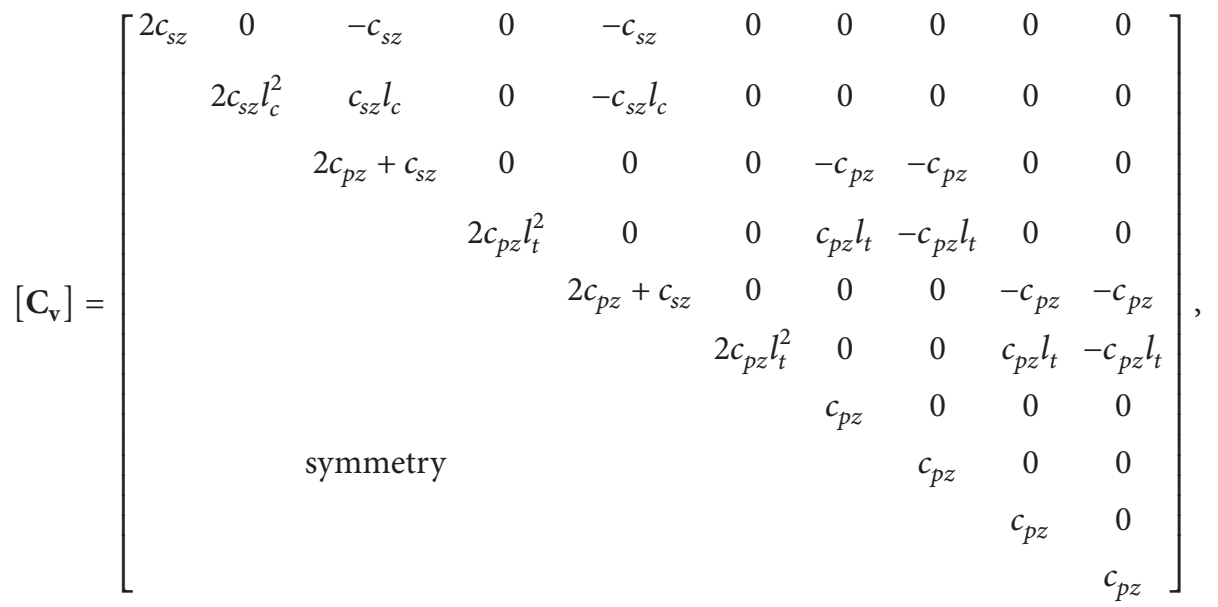

$$
\begin{aligned}
& \left\{F_{v}\right\}=\left\{\begin{array}{llllllllll}
M_{c} g & 0 & M_{t} g & 0 & M_{t} g & 0 & M_{w} g-2 P_{1} & M_{w} g-2 P_{2} & M_{w} g-2 P_{3} & M_{w} g-2 P_{4}
\end{array}\right\} \text {. }
\end{aligned}
$$

The rail is modeled as a simply supported Euler beam with self-weight; the track slab, concrete base, and bridge beam are modeled as a free-free Euler beam with self-weight. The fastener system, emulsified cement asphalt mortar (CA mortar), concrete base-bridge contact, and bridge bearing are regarded as discrete spring-damping systems [20].

Through mechanical analysis, the differential equation describing the Euler beam oscillation in the vertical direction considering the self-weight can be written as follows:

$$
E I \frac{\partial^{4} y(x, t)}{\partial x^{4}}+m_{r} \frac{\partial^{2} y(x, t)}{\partial t^{2}}=F(x, t)+m_{r} g .
$$

The partial differential equations of the vertical vibration of the rail, track slab, concrete base, and bridge beam can be obtained by determining the external forces of the structures.
The fourth-order partial differential equations can be solved using the Ritz method [21, 22], and the basic forms of the second-order ordinary differential equations of the modal coordinates of rail, track slab, concrete base, and bridge beam can be obtained as follows.

Rail

$$
\begin{aligned}
\ddot{q}_{k}(t) & +\frac{E_{r} I_{r}}{m_{r r}}\left(\frac{k \pi}{l_{r}}\right)^{4} q_{k}(t) \\
= & \sum_{j=1}^{4} P_{j}(t) Y_{k}\left(x_{w j}\right)-\sum_{i=1}^{N} F_{r s i}(t) Y_{k}\left(x_{i}\right) \\
& +\frac{g}{k \pi} \sqrt{2 m_{r r} l_{r}}(1-\cos k \pi) \quad\left(k=1 \sim N_{M}\right) .
\end{aligned}
$$


Track Slab

$$
\begin{gathered}
E_{s} I_{s} l_{s} \beta_{s k}^{4} T_{k}(t)+m_{s} l_{s} \ddot{T}_{k}(t) \\
=\sum_{i=1}^{n_{0}} F_{r s i}(t) X_{k}\left(x_{s i}\right)-\sum_{i=1}^{n_{0}} F_{c a i}(t) X_{k}\left(x_{s i}\right) \\
\quad+m_{s} g G_{s}(k) \quad\left(k=1 \sim N_{S}\right) .
\end{gathered}
$$

Concrete Base

$$
\begin{aligned}
E_{b} I_{b} l_{b} \beta_{b k}^{4} B_{k}(t)+m_{b} l_{b} \ddot{B}_{k}(t) \\
=\sum_{i=1}^{m_{0}} F_{c a i}(t) D_{k}\left(x_{b i}\right)-\sum_{i=1}^{m_{0}} F_{f d i}(t) D_{k}\left(x_{b i}\right)
\end{aligned}
$$

$$
+m_{b} g G_{b}(k) \quad\left(k=1 \sim N_{B}\right) .
$$

Bridge Beam

$$
\begin{aligned}
& E_{q} I_{q} l_{q} \beta_{q k}^{4} Q_{k}(t)+m_{q} l_{q} \ddot{Q}_{k}(t) \\
& =\sum_{i=1}^{q_{0}} F_{f d i}(t) L_{k}\left(x_{q i}\right)-\sum_{i=1}^{2} F_{z z i}(t) L_{k}\left(x_{z i}\right) \\
& \quad+m_{q} g G_{q}(k) \quad\left(k=1 \sim N_{Q}\right)
\end{aligned}
$$

where the additional functions of self-weight of the track slab $G_{s}(k)$, concrete base $G_{b}(k)$, and bridge beam $G_{q}(k)$ can be given as follows:

$$
\begin{aligned}
& G_{s}(k)= \begin{cases}l_{s} & (k=1), \\
0 & (k=2), \\
\frac{e^{l_{s} \beta_{s k}}-e^{-l_{s} \beta_{s k}}}{2 \beta_{s k}}+\frac{\sin l_{s} \beta_{s k}}{\beta_{s k}}-C_{k}\left(\frac{e^{l_{s} \beta_{s k}}+e^{-l_{s} \beta_{s k}}}{2 \beta_{s k}}-\frac{\cos l_{s} \beta_{s k}}{\beta_{s k}}\right) & (k>2),\end{cases} \\
& G_{b}(k)= \begin{cases}l_{b} & (k=1), \\
0 & (k=1), \\
\frac{e^{l_{b} \beta_{b k}}-e^{-l_{b} \beta_{b k}}}{2 \beta_{b k}}+\frac{\sin l_{b} \beta_{b k}}{\beta_{b k}}-C_{k}\left(\frac{e^{l_{b} \beta_{b k}}+e^{-l_{b} \beta_{b k}}}{2 \beta_{b k}}-\frac{\cos l_{b} \beta_{b k}}{\beta_{b k}}\right) & (k>2),\end{cases} \\
& G_{q}(k)= \begin{cases}l_{q} & (k=1), \\
0 & (k=2), \\
\frac{e^{l_{q} \beta_{q k}}-e^{-l_{q} \beta_{q k}}}{2 \beta_{q k}}+\frac{\sin l_{q} \beta_{q k}}{\beta_{q k}}-C_{k}\left(\frac{e^{l_{q} \beta_{q k}}+e^{-l_{q} \beta_{q k}}}{2 \beta_{q k}}-\frac{\cos l_{q} \beta_{q k}}{\beta_{q k}}\right) & (k>2) .\end{cases}
\end{aligned}
$$

The dynamic coupling relationship of both the wheel and the rail provides the link between the vehicle subsystem and the rail subsystem $[23,24]$. The Hertz nonlinear elastic contact theory [19] is used to determine the vertical wheelrail contact force:

$$
P_{j}(t)=\left\{\left\{\frac{\left[Z_{w j}(t)-Z_{r}\left(x_{w j}, t\right)-Z_{\text {ir } r j}(t)\right]}{G}\right\}^{3 / 2} \quad\right. \text { when wheel-rail separation. }
$$

The interactions between the rail, track slab, concrete base, bridge beam, and bridge-pier subsystems are described by fastener force, CA mortar reaction force, bridge deck reaction force, and bridge bearing reaction force. These forces are expressed as

$$
\begin{aligned}
F_{r s i}(t)= & C_{p i}\left[\dot{Z}_{r}\left(x_{i}, t\right)-\dot{Z}_{s}\left(x_{i}, t\right)\right] \\
& +K_{p i}\left[Z_{r}\left(x_{i}, t\right)-Z_{s}\left(x_{i}, t\right)\right],
\end{aligned}
$$

$$
\begin{aligned}
F_{c a i}(t)= & C_{a i}\left[\dot{Z}_{s}\left(x_{i}, t\right)-\dot{Z}_{b}\left(x_{i}, t\right)\right] \\
& +K_{a i}\left[Z_{s}\left(x_{i}, t\right)-Z_{b}\left(x_{i}, t\right)\right] \\
F_{f d i}(t)= & C_{f i}\left[\dot{Z}_{b}\left(x_{i}, t\right)-\dot{Z}_{q}\left(x_{i}, t\right)\right] \\
& +K_{f i}\left[Z_{b}\left(x_{i}, t\right)-Z_{q}\left(x_{i}, t\right)+z\left(x_{i}\right)\right] .
\end{aligned}
$$




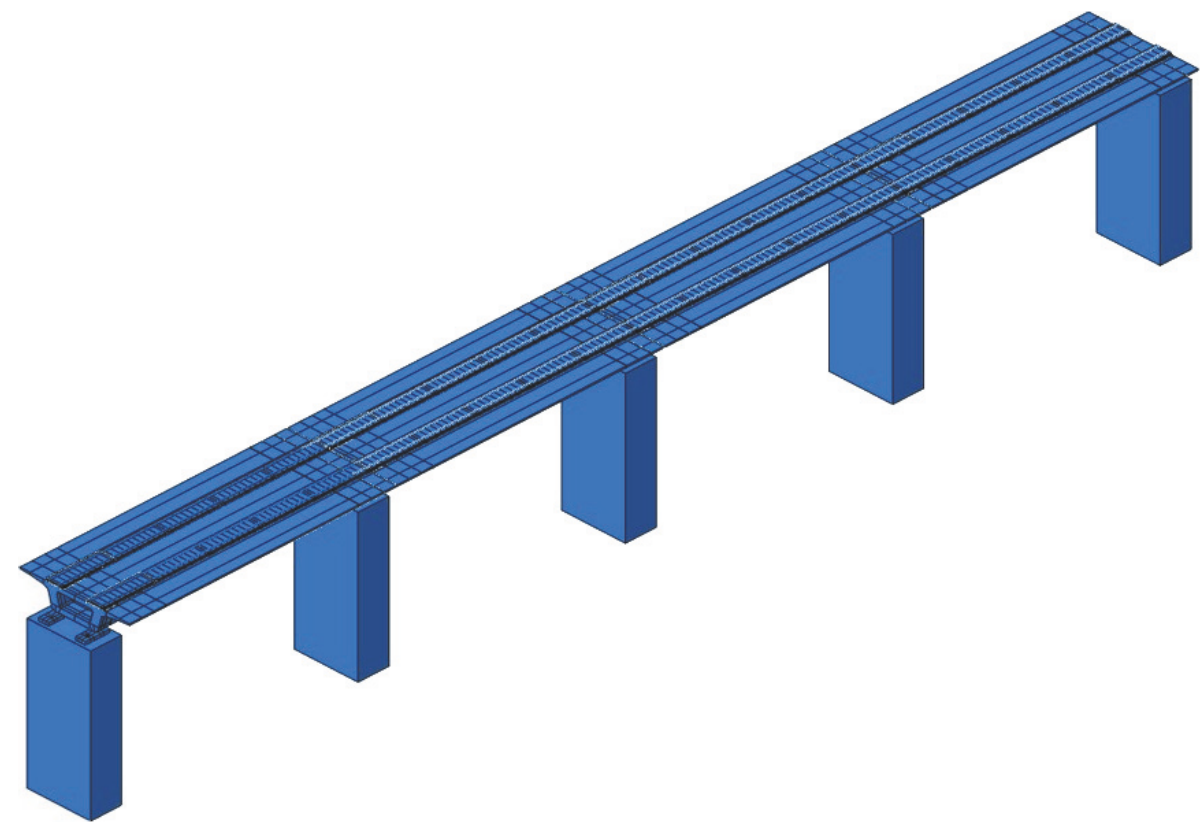

(a)

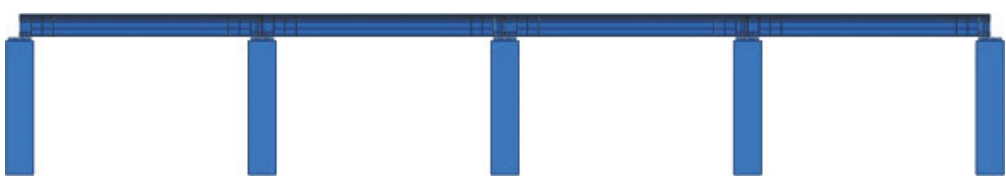

(b)

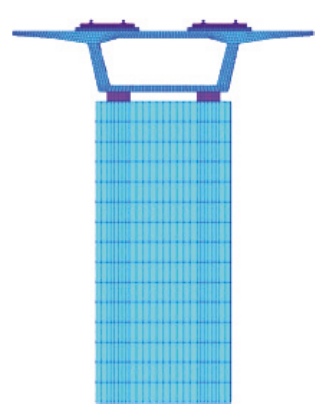

(c)

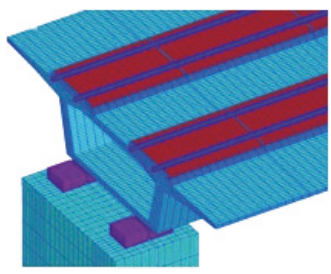

(d)

FIgURe 5: Model geometry: (a) three-dimensional view of whole model; (b) elevation view; (c) cross-section view; (d) detail of model.

The pier differential settlement is determined from the bridge bearing reaction force:

$$
F_{z z i}(t)=C_{z i} \dot{Z}_{q}\left(x_{z i}, t\right)+K_{z i}\left[Z_{q}\left(x_{z i}, t\right)-d_{i}\right] .
$$

Solutions of the proposed train-track-bridge dynamics model considering self-weight adopt the explicit integration method suggested in the literature [25].

2.2. Model Verification. The model suggested herein was verified through a comparative analysis of the outputs calculated by the model with those (1) computed by an FEM model for the static responses due to pier differential settlement regardless of wheel-rail contact force and (2) computed by a train-track-bridge dynamics model in the literature [26] for the vibration responses under a moving train load without the pier differential settlement.

(1) FEM. The finite element program ANSYS was used to establish the 3D FEM model which includes rails, fastener system, track slab, CA mortar, concrete base, bridge beams, bridge bearings, and bridge piers (see Figure 5). The rails were modeled with beam elements BEAM188, and the other structures were modeled with hexahedral solid elements SOLID185. The bridge in the 3D FEM model consisted of four beams which were all standard box beams in China with a $32 \mathrm{~m}$ length of the span (i.e., the total length of the bridge is $128 \mathrm{~m}$ ). The bridge was supported on five piers among which the 3rd pier was assumed to have a $10 \mathrm{~mm}$ settlement compared with the other piers (i.e., the pier differential settlement is $10 \mathrm{~mm}$ ). The parameters of the FEM model and the proposed model are listed in Table 1.

Figure 6(a) shows the comparison of the vertical displacement of the rail obtained from the proposed model (with self-weight) and 3D FEM simulation due to a $10 \mathrm{~mm}$ pier differential settlement regardless of wheel-rail contact force. The vertical displacement of the rail in the two models shows good agreement and both present an inverted V-shape (see Figure 6(a)). Because of the continuity of the rail and discontinuity of the bridge structures in the longitudinal direction, the maximum value of the vertical displacement of the rail is less than $10 \mathrm{~mm}$, thus leading to abnormal changes of the fastener force (see Figure 6(b)). As shown 
TABLE 1: Parameters of FEM model and the proposed model.

\begin{tabular}{|c|c|c|c|}
\hline \multirow{2}{*}{ Structure } & \multirow{2}{*}{ Parameter (unit) } & \multicolumn{2}{|c|}{ Value } \\
\hline & & FEM model & The proposed model \\
\hline \multirow{3}{*}{ Steel rail } & Elastic modulus $\left(\mathrm{N} / \mathrm{m}^{2}\right)$ & & \\
\hline & Inertia moment $\left(\mathrm{m}^{4}\right)$ & & \\
\hline & Linear density $(\mathrm{kg} / \mathrm{m})$ & & \\
\hline \multirow{2}{*}{ Fastener } & Stiffness (N/m) & & \\
\hline & Damping $(\mathrm{kN} \mathrm{s} / \mathrm{m})$ & - & 75 \\
\hline \multirow{5}{*}{ Track slab } & Width (m) & & \\
\hline & Thickness (m) & & \\
\hline & Elastic modulus $\left(\mathrm{N} / \mathrm{m}^{2}\right)$ & & \\
\hline & Poisson's ratio & 0.2 & - \\
\hline & Density $\left(\mathrm{kg} / \mathrm{m}^{3}\right)$ & & \\
\hline \multirow{5}{*}{ CA mortar } & Stiffness $(\mathrm{N} / \mathrm{m})$ & - & $1.25 \times 10^{9}$ \\
\hline & Damping (kN s/m) & - & 34.58 \\
\hline & Elastic Modulus $\left(\mathrm{N} / \mathrm{m}^{2}\right)$ & $200 \times 10^{6}$ & - \\
\hline & Poisson's ratio & 0.31 & - \\
\hline & Density $\left(\mathrm{kg} / \mathrm{m}^{3}\right)$ & 1800 & - \\
\hline \multirow{5}{*}{ Concrete base } & Width (m) & & \\
\hline & Thickness (m) & & \\
\hline & Elastic modulus $\left(\mathrm{N} / \mathrm{m}^{2}\right)$ & & \\
\hline & Poisson's ratio & 0.2 & - \\
\hline & Density $\left(\mathrm{kg} / \mathrm{m}^{3}\right)$ & & \\
\hline \multirow{3}{*}{ Bridge beam } & Elastic Modulus $\left(\mathrm{N} / \mathrm{m}^{2}\right)$ & & \\
\hline & Poisson's ratio & 0.2 & - \\
\hline & Density $\left(\mathrm{kg} / \mathrm{m}^{3}\right)$ & & \\
\hline \multirow{2}{*}{ Bridge bearing } & Stiffness $(\mathrm{N} / \mathrm{m})$ & & \\
\hline & Damping (kN s/m) & - & $7.5 \times 10^{4}$ \\
\hline
\end{tabular}

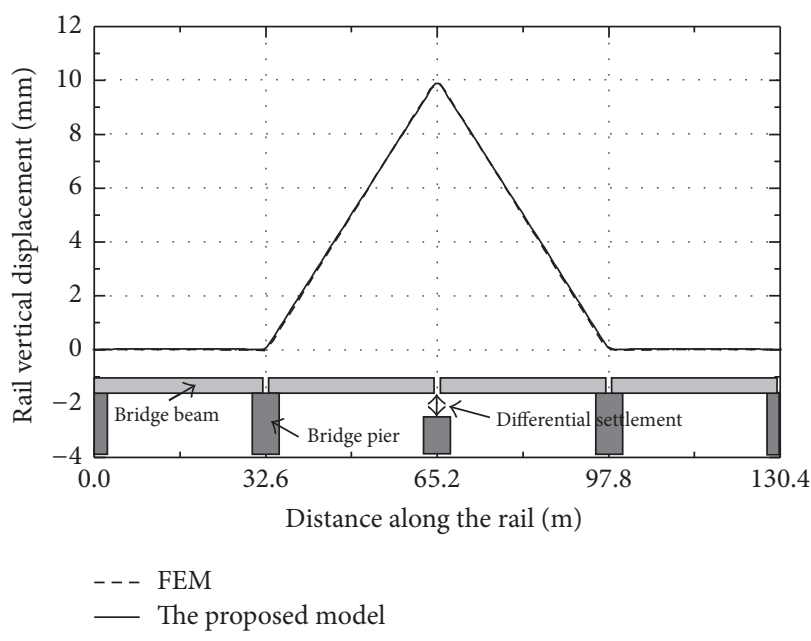

(a)

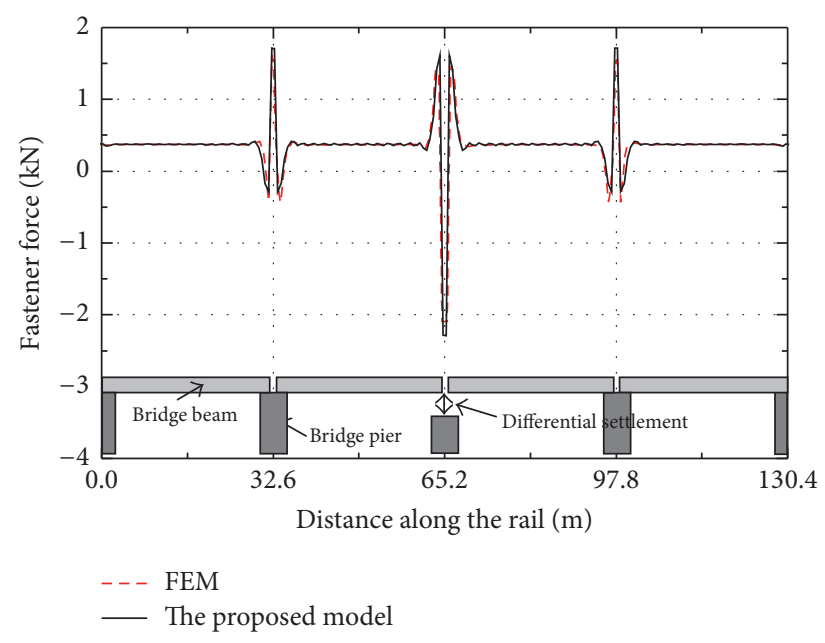

(b)

FIgURE 6: Comparison of static responses: (a) rail vertical displacement and (b) fastener force.

in Figure 6(b), the fastener force of the two models also shows a good agreement in magnitude and frequency. One may conclude that the proposed model is accurate and can consider the self-weight.
(2) Model in the Literature [26]. A comparison of the vertical acceleration of the bridge deck, the vertical displacement magnification factor, and vertical acceleration of the vehicle body under a moving train load regardless of the pier 


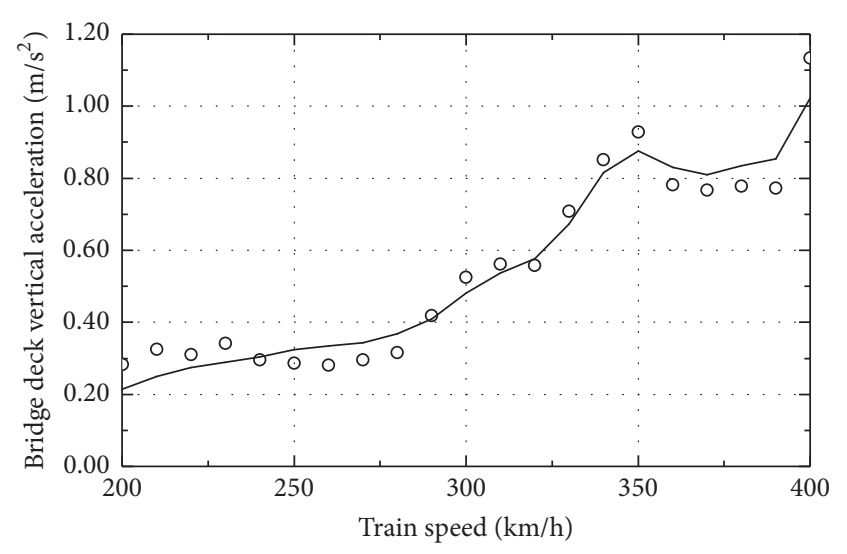

○ Results in the literature - Proposed model

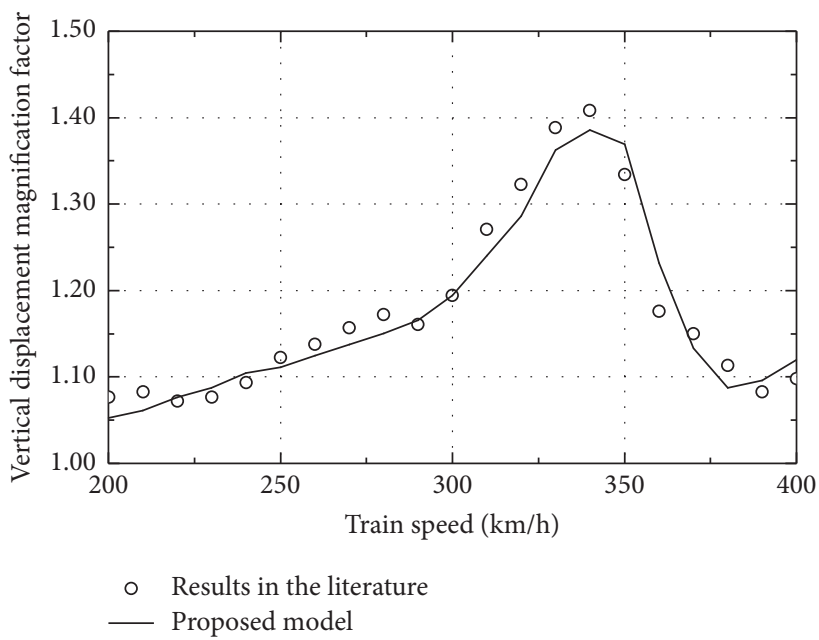

(b)

(a)

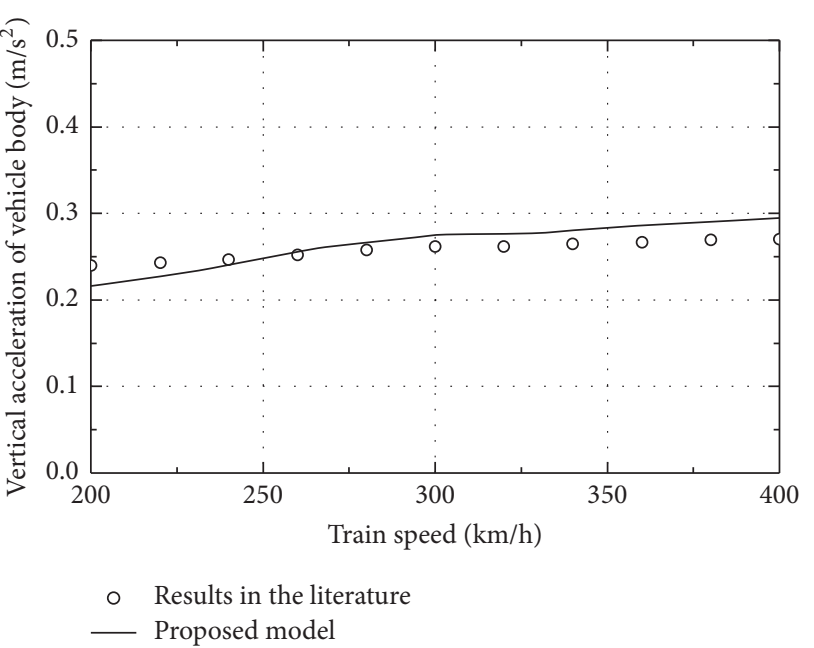

(c)

FIGURE 7: Comparison of dynamic responses: (a) vertical acceleration of bridge deck, (b) vertical displacement magnification factor of midspan, and (c) vertical acceleration of vehicle body.

differential settlement was made between the result of the proposed model and that calculated in the literature [26]. The calculation was conducted for an Italian ETR500Y high-speed train running at different speeds regardless of the pier differential settlement. The bridge is composed of seven simply supported composite spans of $43.6 \mathrm{~m}$. Figure 7 compares the vertical acceleration of the bridge deck (see Figure 7(a)), vertical displacement magnification factor of the mid-span (see Figure 7(b)), and vertical acceleration of the vehicle body (see Figure 7(c)) in the proposed model and the literature.

As shown in Figure 7, the results obtained from the literature and the proposed model show a reasonable agreement. For example, the vertical acceleration of the bridge deck and vertical displacement magnification factor both increase with the train speed in general and reach a peak value at a train speed of $350 \mathrm{~km} / \mathrm{h}$. The difference in the results from the literature and proposed model may be partly explained by the fact that the track structure parameters in the proposed model may not be exactly the same as those in the literature.

From the comparisons shown in Figures 6 and 7 with the other models, it is evident that the proposed model can calculate the static and dynamic response of the system due to pier differential settlement with a sufficient degree of accuracy. Compared to the 3D FEM simulation, the proposed model is considerably more efficient computationally but is still capable of computing the static response of the system accurately when pier differential settlement occurs. Note that each simulation of the proposed approach requires approximately five minutes of CPU time on an Intel Core i5 processors, while each FEM-based model will have to cost several hours of CPU time. Compared to the integral model in the literature, the proposed model takes into consideration the effect of structure self-weight, which is more representative of the actual situation and thus can be used to calculate the dynamic response of the system due to the pier differential settlement. 


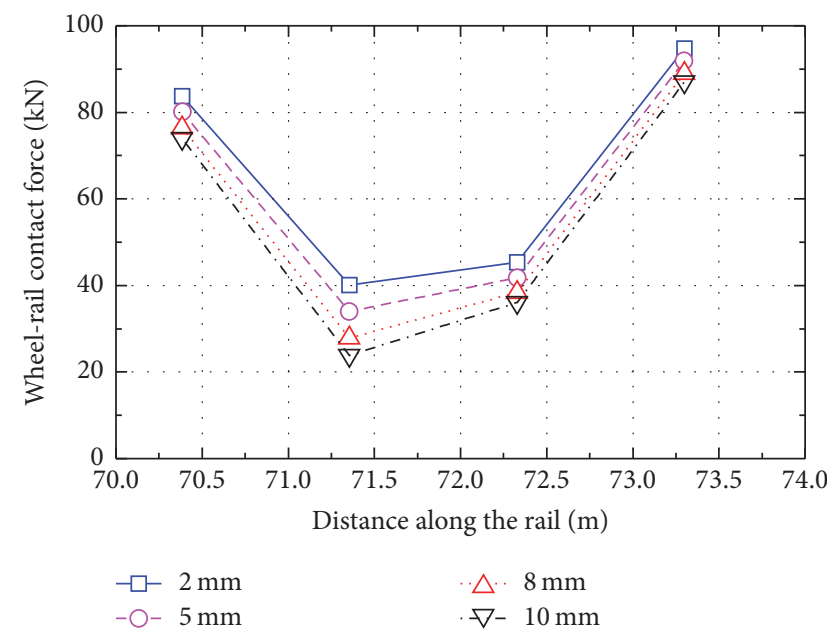

(a)

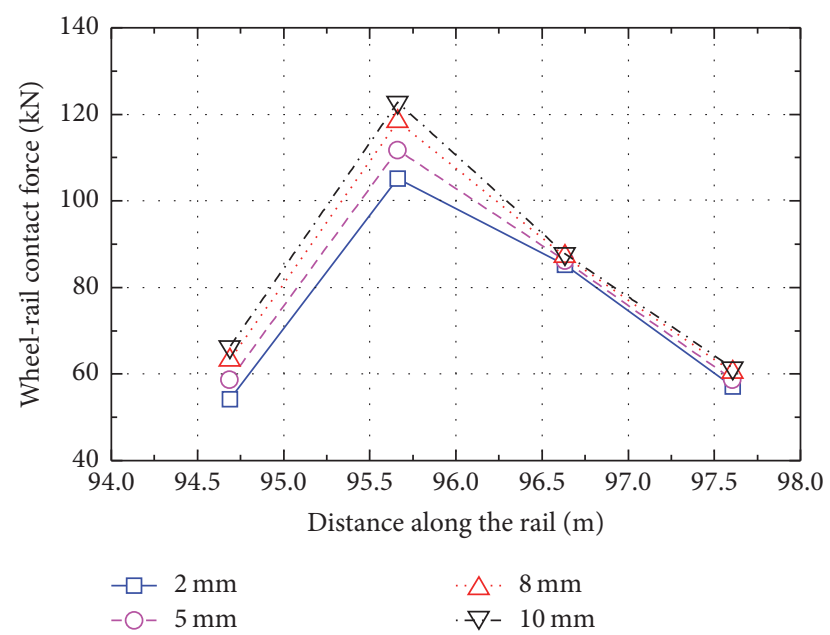

(b)

FiguRE 8: Wheel-rail contact force for different pier settlement values: (a) position A and (b) position B.

\section{Effect of Pier Differential Settlement}

To obtain a deep insight into the limits of pier differential settlement as a part of the standards for construction and maintenance, a study was carried out to determine the functional performance criteria associated with train safety, stability, and service life of the fastener system as a function of the following:

(i) Amplitude of pier differential settlement: $2 \mathrm{~mm}$, $5 \mathrm{~mm}, 8 \mathrm{~mm}$, and $10 \mathrm{~mm}$

(ii) Train speed: $200 \mathrm{~km} / \mathrm{h}, 250 \mathrm{~km} / \mathrm{h}, 300 \mathrm{~km} / \mathrm{h}$, and $350 \mathrm{~km} / \mathrm{h}$

(iii) Span of the simply supported beam bridge: $24 \mathrm{~m}$ and $32 \mathrm{~m}$ (note that a span of $24 \mathrm{~m}$ or $32 \mathrm{~m}$ is most widely used in China)

The measures of functional performance criteria were chosen for the following:

(a) Stability: the maximum vertical acceleration of a train, which was in keeping with a number of railway organizations, was used as a measure of stability. In Chinese design standards, an upper limit of the vertical acceleration $0.13 \mathrm{~g}$ is specified [27].

(b) Safety: the likelihood of the derailment of a train is commonly measured by the wheel unloading rate and an upper limit of 0.9 is suggested in the literature [27].

(c) Service time of the fastener system: the service time of the fastener system is partly related to fastener force.

The train chosen in the calculation is a CRH3 EMU train with an axle load of approximately $16 t$, and the bridge is the standard simply supported beam bridge with CRTS I slab track. There are nine piers in the model and only the middle pier of the bridge has a certain settlement.

3.1. Wheel Unloading Rate. Figure 8 shows the computed wheel-rail contact force at positions A and B (indicated in
Figure 2) for four chosen pier differential settlements and a $24 \mathrm{~m}$ length of the span when the train speed is $350 \mathrm{~km} / \mathrm{h}$. It can be seen from the figure that the wheel-rail contact force at position A decreases with the pier differential settlement. In contrast, the wheel-rail contact force at position B increases with the pier differential settlement. The reason for the effect of pier differential settlement on the wheel-rail contact force shown in Figure 8 can be explained as follows. When the train passes through position $\mathrm{A}$, the train will experience an effect of centrifugal force because of the settlement curve of the rail according to the pier differential settlement. The larger is the pier differential settlement, the greater is the centrifugal force experienced by the train and the smaller is the wheel-rail contact force. The condition of the wheel-rail contact force at position $\mathrm{B}$ can also be explained using a similar theory, but the train experiences a centripetal force instead of centrifugal force.

Figure 9 shows the maximum wheel unloading rate at positions $\mathrm{A}$ and $\mathrm{B}$ as a function of the pier differential settlement. It can be seen that the wheel unloading rate increases with the pier differential settlement for all calculation conditions considered. The wheel unloading rate with a $24 \mathrm{~m}$ length of span is slightly larger than that with a $32 \mathrm{~m}$ length of span. The maximum of the wheel unloading rate increases with train speed as expected, with a corresponding decrease in safety, but for all the considered train speeds, its maximum value of 0.695 is well below the allowable limit (i.e., $0.9)$.

3.2. Vertical Acceleration of Vehicle Body. Figure 10 shows the vertical acceleration as a function of running distance with different pier differential settlement for $24 \mathrm{~m}$ of bridge beam at a speed of $350 \mathrm{~km} / \mathrm{h}$. As shown in Figure 10, the vertical acceleration in spans $3 \sim 6$ is affected by the pier differential settlement. The overall trend for the change of vertical acceleration curve is an initial increase at the $3 \mathrm{rd}$ span before a decrease when the train comes to the 4 th span. The acceleration reaches its minimum at the position of the pier 


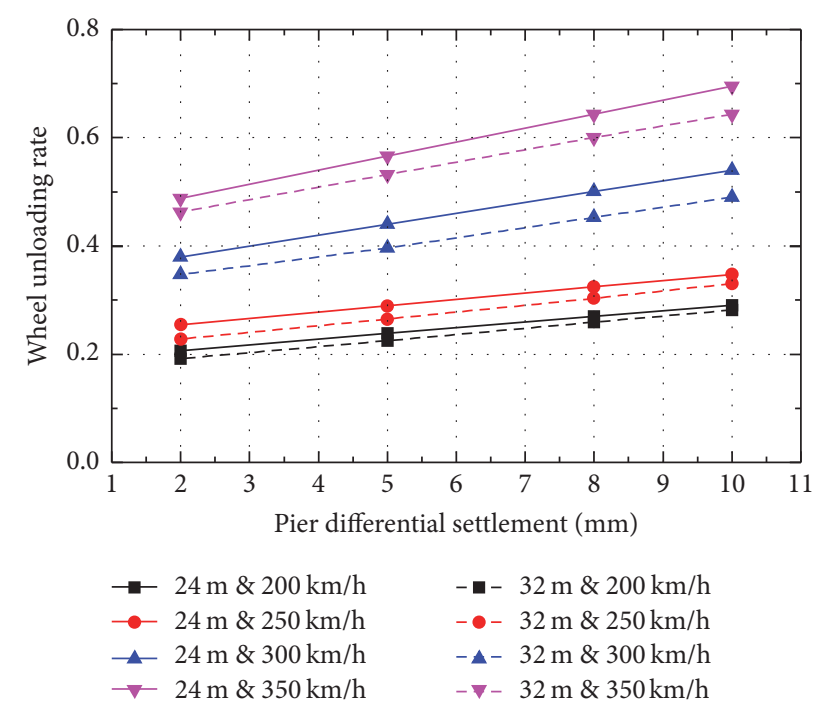

FIGURE 9: Maximum wheel unloading rate at different pier settlement values.

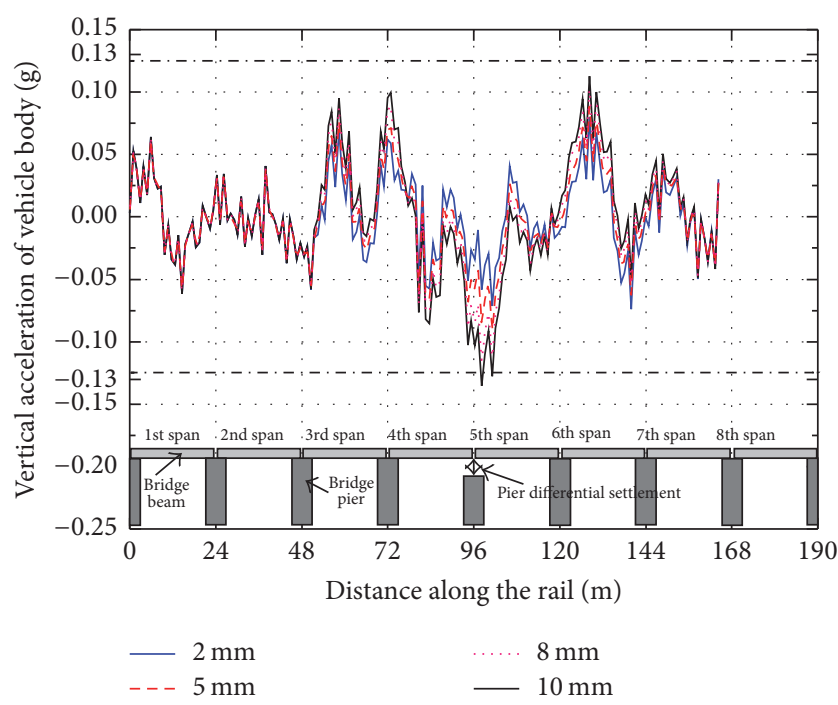

FIgURE 10: Vertical acceleration of the vehicle body at different pier settlement values.

that has a settlement and then generally returns to its initial state.

Figure 11 shows the maximum vertical acceleration (absolute value) as a function of the pier differential settlement for bridge beam lengths of $24 \mathrm{~m}$ and $32 \mathrm{~m}$. The maximum vertical acceleration increases with the pier differential settlement, and the acceleration with a $24 \mathrm{~m}$ length of the bridge beam is slightly larger than that with a $32 \mathrm{~m}$ length of the bridge beam. The vertical acceleration reaches its maximum when the pier differential settlement is $10 \mathrm{~mm}$ and the train speed is $350 \mathrm{~km} / \mathrm{h}$, respectively, $0.135 \mathrm{~g}$ for a $24 \mathrm{~m}$ length of the bridge beam, and $0.131 \mathrm{~g}$ for a $32 \mathrm{~m}$ length of the bridge beam. The two maximum values of vertical acceleration both exceed the maximum allowable limit stipulated in the Chinese standards

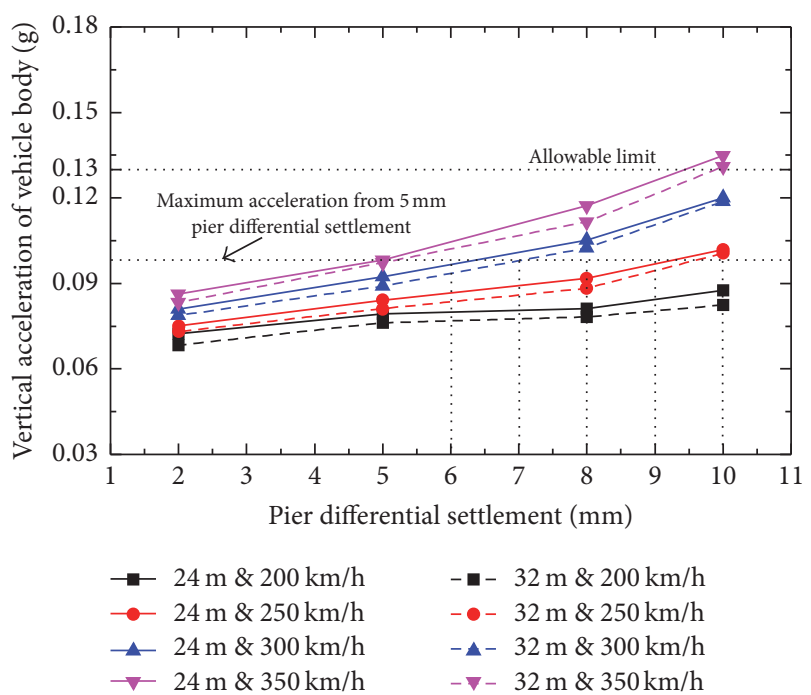

FIGURE 11: Maximum vertical acceleration of the vehicle body at different pier settlement values.

(i.e., $0.13 \mathrm{~g}$ ). As mentioned in the Introduction, the train speed must be limited if the pier differential settlement exceeds the allowable limit. The reason for the speed limit is to cause the system dynamic response to the exceeding pier differential settlement condition to have a value below that of the normal pier differential settlement condition (when the pier differential settlement does not reach the allowable limit). The maximum vertical acceleration of the vehicle body when the pier differential settlement is $5 \mathrm{~mm}$ (i.e., the allowable limit of the pier differential settlement for two adjacent piers) is approximately $0.097 \mathrm{~g}$, so the limit speed can be determined from Figure 11 for consideration of passenger comfort as listed in Table 2.

3.3. Fastener Force. As an important component of track structures to link rails and ties, the fastener system must have sufficient strength and durability. For the simply supported beam bridge, the bridge beams are discontinuous in the longitudinal direction at the piers, while the rail is continuous. As a result, the rail deformation differs from the bridge beam deformation when a pier differential settlement occurs, thus leading to initial fastener forces before the train arrives. Figure 12 shows the initial fastener force at a pier differential settlement of $2 \mathrm{~mm}, 5 \mathrm{~mm}, 8 \mathrm{~mm}$, and $10 \mathrm{~mm}$ for a bridge beam length of $24 \mathrm{~m}$. Note that a compressive initial fastener force is positive and the tensile force is negative. As shown in Figure 12, an abnormal change occurs at the position of the pier that has a settlement and the two adjacent piers. The bending direction of the rail at the position of the pier, which has a settlement, is opposite to that at the position of the two adjacent piers, meaning that the shape of the initial fastener force curve at two kinds of position is approximately inverted. The initial fastener force (compressive force and tensile force with absolute value) increases with the pier differential settlement and the maximum compressive and tensile forces are listed in Table 3. 
TABLE 2: Speed limit for exceeding pier differential settlement.

\begin{tabular}{lccccc}
\hline Pier differential settlement $(\mathrm{mm})$ & 6 & 7 & 8 & 10 \\
\hline Speed limit $(\mathrm{km} / \mathrm{h})$ & 300 & 250 & 250 & 250 & 200 \\
\hline
\end{tabular}

TABLE 3: Maximum fastener compressive and tensile forces.

\begin{tabular}{lccccc}
\hline \multirow{2}{*}{ Span of the bridge beams } & Initial fastener force & \multicolumn{3}{c}{ Pier differential settlement (mm) } \\
& & 2 & 5 & 8 & 10 \\
\hline \multirow{2}{*}{$24 \mathrm{~m}$} & Maximum tensile force $(\mathrm{kN})$ & 0.294 & 1.285 & 2.276 & 2.937 \\
& Maximum compressive force $(\mathrm{kN})$ & 0.712 & 1.238 & 1.733 & 2.065 \\
\multirow{2}{*}{$32 \mathrm{~m}$} & Maximum tensile force $(\mathrm{kN})$ & 0.154 & 0.956 & 1.755 & 1.449 \\
& Maximum compressive force $(\mathrm{kN})$ & 0.647 & 1.048 & 1.717 \\
\hline
\end{tabular}

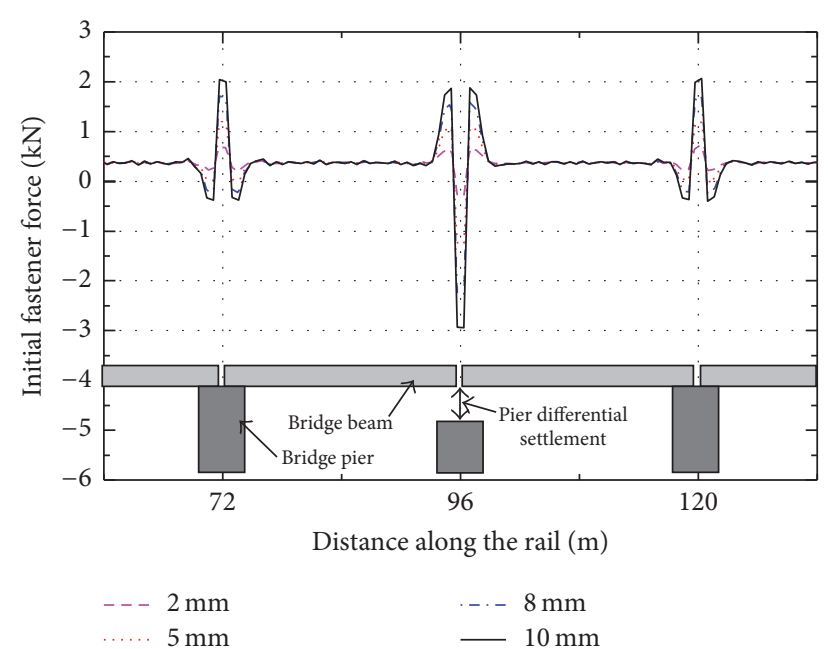

FIGURE 12: Initial fastener force before train arrives.

As shown in Table 3, the maximum tensile force and compressive force for a $24 \mathrm{~m}$ length of bridge beam are both greater than those for a $32 \mathrm{~m}$ length of bridge beam. When the pier differential settlement is $10 \mathrm{~mm}$, the initial fastener force reaches its maximum, namely, $2.937 \mathrm{kN}$ (tensile force) and $2.065 \mathrm{kN}$ (compressive force) for a span of $24 \mathrm{~m}$ and $2.286 \mathrm{kN}$ (tensile force) and $1.717 \mathrm{kN}$ (compressive force) for a span of $32 \mathrm{~m}$. The time history characteristics of the fastener force due to the train loading differ with the fasteners that have different initial forces. Further analysis shows that some of the fasteners are always in compression with and without train loading (see Figure 13 for the fastener that has a compressive initial force), while some fasteners experience both compressive and tensile forces as shown in Figure 13. Those that experience both compressive and tensile cyclic loading forces are likely to have lower service lives than those subjected to compressive forces only [28].

\section{Conclusions}

This paper describes a numerical model for a coupled dynamics analysis of vertical responses in a train-track-bridge system. The performances of the model are compared with a

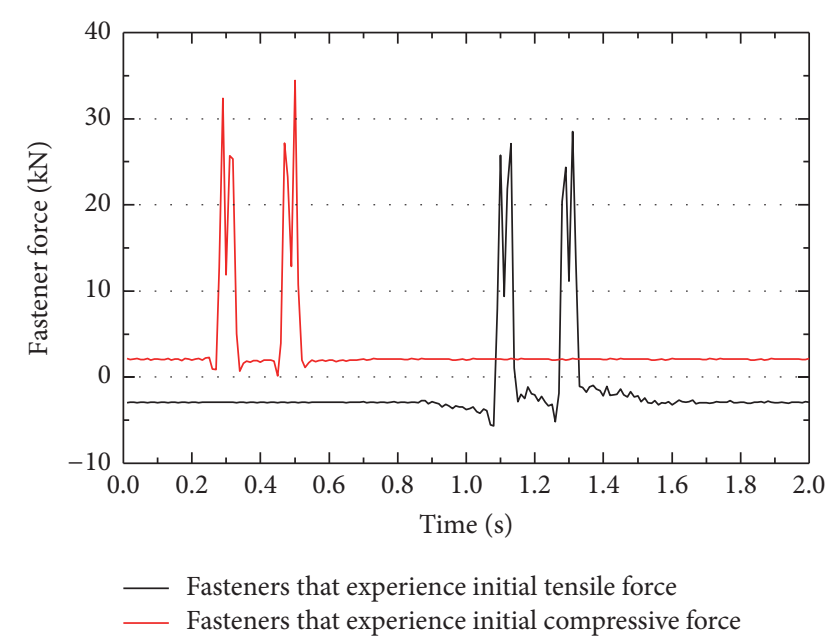

FIGURE 13: Fastener forces of fasteners subjected to compressive forces alone and fasteners subjected to both compressive and tensile cyclic forces.

3D FEM and numerical model in the literature. Compared to the existing models, the proposed model has two advantages: (i) the model considers the effect of structure self-weight; thus, it can be used to calculate the dynamic response of the system due to the pier differential settlement; (ii) the model is considerably more computationally efficient, and it therefore can be used in environments that do not have access to the computing facilities that are required to run similar FEMs.

The developed model was used to investigate the influence of the pier differential settlement, train speed, and length of the bridge beam on measures of track performance associated with passenger ride quality, railway vehicle safety, and fastener forces. The following findings may be drawn from the analysis.

(1) The wheel unloading rate increases with both train speed and pier differential settlement. The wheel unloading rate for a $24 \mathrm{~m}$ length of bridge beam is slightly larger than that for a $32 \mathrm{~m}$ length of bridge beam, and for all the considered train speeds, its maximum value of 0.695 is well below the allowable limit. 
(2) The vehicle vertical acceleration increases with the pier differential settlement and train speed. The maximum vertical acceleration, respectively, $0.135 \mathrm{~g}$ for a $24 \mathrm{~m}$ length of bridge beam and $0.131 \mathrm{~g}$ for a $32 \mathrm{~m}$ length of bridge beam, exceeds the maximum allowable limit stipulated in the Chinese standards. On this basis, the speed limit for the exceeding pier differential settlement is determined for comfort consideration.

(3) The beams of a simply supported beam bridge are discontinuous in the longitudinal direction at piers but the rail is continuous, thus leading to initial fastener forces before the train arrives. The fasteners that have an initial compressive force are always in compression with and without train loading, while fasteners that have an initial tensile force experience both compressive and tensile forces and are likely to have lower service lives than those that are subjected to compressive forces alone.

\section{Notations}

$\left\{A_{\mathrm{v}}\right\}: \quad$ Acceleration vectors of vehicle system

$\left\{V_{v}\right\}: \quad$ Velocity vectors of vehicle system

$\left\{X_{v}\right\}: \quad$ Displacement vectors of vehicle system

$\left\{F_{v}\right\}: \quad$ Load vectors of vehicle system

$\left[\mathbf{M}_{\mathbf{v}}\right]$ : Mass matrices of vehicle system

$\left[\mathbf{C}_{\mathbf{v}}\right]$ : Damping matrices of vehicle system

$\left[\mathbf{K}_{\mathbf{v}}\right]$ : Stiffness matrices of vehicle system

$M_{c}$ : $\quad$ Vehicle body mass

$J_{c}: \quad$ Moment of inertia of vehicle body

$M_{t}: \quad$ Bogie frame mass

$J_{t}$ : $\quad$ Moment of inertia of bogie frame

$M_{w}$ : Wheel set mass

$k_{s z}$ : $\quad$ Secondary suspension stiffness

$l_{c}: \quad$ Distance between bogie centers

$k_{p z}: \quad$ Primary suspension stiffness

$l_{t}: \quad$ Bogie wheelbase

$c_{s z}: \quad$ Secondary suspension damping

$c_{p z}: \quad$ Primary suspension damping

$P_{1} \sim P_{4}$ : Wheel-rail contact force

$y(x, t)$ : Vertical displacement of the Euler beam

$m_{r}$ : $\quad$ Mass of per unit length of the Euler beam

EI: $\quad$ Flexural rigidity of the Euler beam

$F(x, t)$ : External force

$N$ : Number of fasteners

$n_{0}$ : Number of track slab coordinate nodes

$m_{0}$ : Number of concrete base coordinate nodes

$q_{0}$ : Number of bridge beam coordinate nodes

$F_{r s i}(t): \quad$ Fastener force

$F_{c a i}(t)$ : CA mortar reaction force

$F_{f d i}(t)$ : Bridge deck reaction force

$F_{z z i}(t)$ : Bridge bearing force

$q_{k}(t)$ : Modal coordinates of the rail

$T_{k}(t)$ : Modal coordinates of the track slab

$B_{k}(t)$ : Modal coordinates of the concrete base

$Q_{k}(t)$ : Modal coordinates of the bridge beam

$Y_{k}$ : Orthogonal function department of the rail
$X_{k}$ : Orthogonal function department of the track slab

$D_{k}$ : Orthogonal function department of the concrete base

$L_{k}$ : Orthogonal function department of the bridge

$\beta_{s k}$ : Constants of the track slab

$\beta_{b k}$ : Constants of the concrete base

$\beta_{q k}$ : Constants of the bridge beam

$G_{s}(k)$ : Functions of the track slab self-weight

$G_{b}(k)$ : Functions of the concrete base self-weight

$G_{q}(k)$ : Functions of the bridge beam self-weight

$C_{k}$ : Coefficient of the free beam

$Z_{w j}(t)$ : Displacement of wheel set

$Z_{\text {irrj }}(t)$ : Track irregularity at the position of wheel set

$G$ : Wheel-rail contact constant

$\dot{Z}_{r}\left(x_{i}, t\right)$ : Vertical velocity of the rail

$Z_{r}\left(x_{i}, t\right)$ : Vertical displacement of the rail

$\dot{Z}_{s}\left(x_{i}, t\right)$ : Vertical velocity of the track slab

$Z_{s}\left(x_{i}, t\right)$ : Vertical displacement of the track slab

$\dot{Z}_{b}\left(x_{i}, t\right)$ : Vertical velocity of the concrete base

$Z_{b}\left(x_{i}, t\right)$ : Vertical displacement of the concrete base

$\dot{Z}_{q}\left(x_{i}, t\right)$ : Vertical velocity of the bridge beams

$Z_{q}\left(x_{i}, t\right)$ : Vertical displacement of the bridge beams

$z\left(x_{i}\right)$ : Bridge precamber

$C_{p i}: \quad$ Damping of the fastener system

$C_{a i}$ : $\quad$ Damping of the CA mortar

$C_{f}: \quad$ Damping of the bridge deck

$K_{p i}: \quad$ Stiffness of the fastener system

$K_{a i}: \quad$ Stiffness of the CA mortar

$K_{f i}$ : Stiffness of the bridge deck

$d_{i}$ : $\quad$ Pier settlement value

$C_{z i}$ : $\quad$ Damping of the bridge bearing

$K_{z i}: \quad$ Stiffness of the bridge bearing

\section{Conflicts of Interest}

The authors declare that there are no conflicts of interest regarding the publication of this paper.

\section{Acknowledgments}

The work described in this paper was supported by the National Natural Science Foundation of China (51478353).

\section{References}

[1] W. M. Zhai and H. Xia, Traintrackbridge dynamic interaction: theory and engineering application, Science Press, China, 1st edition, 2011.

[2] TB., TB 10002.5: 2005, Code for Design on Subsoil and Foundation of Railway Bridge and Culvert.

[3] TB 10621: 2014, Code for Design of High Speed Railway.

[4] Y.-B. Yang and B.-H. Lin, "Vehicle-bridge interaction analysis by dynamic condensation method," Journal of Structural Engineering, vol. 121, no. 11, pp. 1636-1643, 1995. 
[5] H. Azimi, K. Galal, and O. A. Pekau, "A numerical element for vehicle-bridge interaction analysis of vehicles experiencing sudden deceleration," Engineering Structures, vol. 49, pp. 792805, 2013.

[6] M. Ziyaeifar, "Interaction study of train-bridge-track systems using Maxwell model," Vehicle System Dynamics, vol. 43, no. 11, pp. 771-794, 2005.

[7] S. Invernizzi, G. Lacidogna, A. Manuello, and A. Carpinteri, "AE monitoring and numerical simulation of a two-span model masonry arch bridge subjected to pier scour," Strain, vol. 47, no. 2, pp. 158-169, 2011.

[8] W. Zhai, H. Xia, C. Cai et al., "High-speed train-track-bridge dynamic interactions-part I: theoretical model and numerical simulation," International Journal of Rail Transportation, vol. 1, no. 1-2, pp. 3-24, 2013.

[9] N. Zhang, H. Xia, and W. W. Guo, "Vehicle-bridge interaction analysis under high-speed trains," Journal of Sound and Vibration, vol. 309, no. 3-5, pp. 407-425, 2008.

[10] Z. P. Hu, K. Z. Xie, H. Zhu, and P. Wang, "Effect on continuous welded rail caused by bridge pier settlement of large-span bridge with high-rise piers," Railway Standard Design, vol. 10, p. 2326, 2014.

[11] Z. W. Chen, Y. Sun, and W. M. Zhai, "Mapping relationship between pier settlement and rail deformation of high-speed railways-part (i): the unit slab track system," Scientia Sinica Technologica, vol. 44, no. 7, pp. 770-777, 2014.

[12] Z. W. Chen, Y. Sun, and W. M. Zhai, "Mapping relationship between pier settlement and rail deformation of high-speed railways-part (ii): the longitudinal connected ballastless track system," Scientia Sinica Technologica, vol. 44, no. 7, pp. 778-785, 2014.

[13] J. D. Yau, "Response of a maglev vehicle moving on a series of guideways with differential settlement," Journal of Sound and Vibration, vol. 324, no. 3-5, pp. 816-831, 2009.

[14] J. D. Yau, "Response of a train moving on multi-span railway bridges undergoing ground settlement," Engineering Structures, vol. 31, no. 9, pp. 2115-2122, 2009.

[15] H. Xia and N. Zhang, "Dynamic analysis of railway bridge under high-speed trains," Computers and Structures, vol. 83, no. 23, pp. 1891-1901, 2005.

[16] H. Xia, N. Zhang, and W. W. Guo, "Analysis of resonance mechanism and conditions of train-bridge system," Journal of Sound and Vibration, vol. 293, no. 3, pp. 810-822, 2006.

[17] K. P. Wang, H. Xia, W. W. Guo et al., "Influence of uneven settlement of bridge piers on running safety of high-speed trains," Journal of Vibration and Shock, vol. 33, no. 6, pp. 137142, 2014.

[18] Y.-M. Cao, H. Xia, K.-P. Wang, and D.-D. Kong, "Pre-evaluation of impact of foundation construction near existing railway bridge on running train," Journal of the China Railway Society, vol. 35, no. 3, pp. 95-101, 2013.

[19] W. M. Zhai, Vehicle-Track Coupling Dynamics, Science Press, China, 3rd edition, 2007.

[20] X. Zhang, S. Zhou, Q. Gong, and X. Yang, "Effect of subgrade differential settlement on dynamic response of vehicle and slab track vertical coupled system," Journal of Tongji University, vol. 43, no. 8, pp. 1187-1253, 2015.

[21] E. Ventsel and T. Krauthammer, Thin Plates and Shells: Theory, Analysis and Applications, CRC press, New York, NY, USA, 1st edition, 2001.
[22] A. K. Chopra, DyNamics of Structures, Prentice Hall, New Jersey, NJ, USA, 1st edition, 1995.

[23] B. Allotta, P. D’Adamio, L. Marini, E. Meli, L. Pugi, and A. Rindi, "A new strategy for dynamic weighing in motion of railway vehicles," IEEE Transactions on Intelligent Transportation Systems, vol. 16, no. 6, pp. 3520-3533, 2015.

[24] B. Allotta, P. D’Adamio, E. Meli, and L. Pugi, "Development of a new time domain-based algorithm for train detection and axle counting," Vehicle System Dynamics, vol. 53, no. 12, pp. 18501875,2015 .

[25] W.-M. Zhai, "Two simple fast integration methods for largescale dynamic problems in engineering," International Journal for Numerical Methods in Engineering, vol. 39, no. 24, pp. 4199$4214,1996$.

[26] W. W. Guo, H. Xia, G. De Roeck, and K. Liu, "Integral model for train-track-bridge interaction on the Sesia viaduct: dynamic simulation and critical assessment," Computers and Structures, vol. 112-113, pp. 205-216, 2012.

[27] GB5599-85:1985, Evaluation standard of the dynamic characteristic of railway vehicle.

[28] J. Shi, M. P. N. Burrow, A. H. Chan et al., "Measurements and simulation of the dynamic responses of a bridge-embankment transition zone below a heavy haul railway line," Journal of Rail and Rapid Transit, vol. 227, no. 3, pp. 254-268, 2013. 


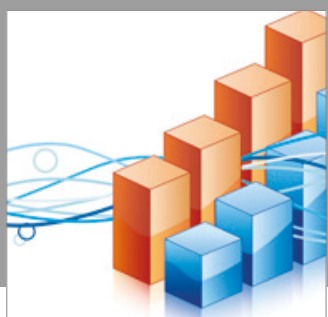

Advances in

Operations Research

vatersals

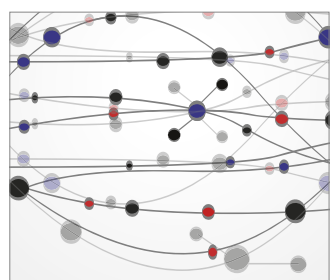

\section{The Scientific} World Journal
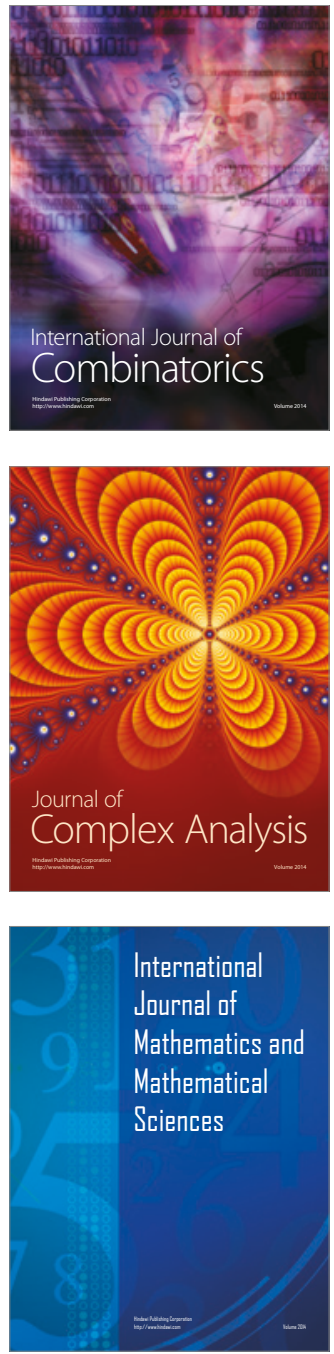
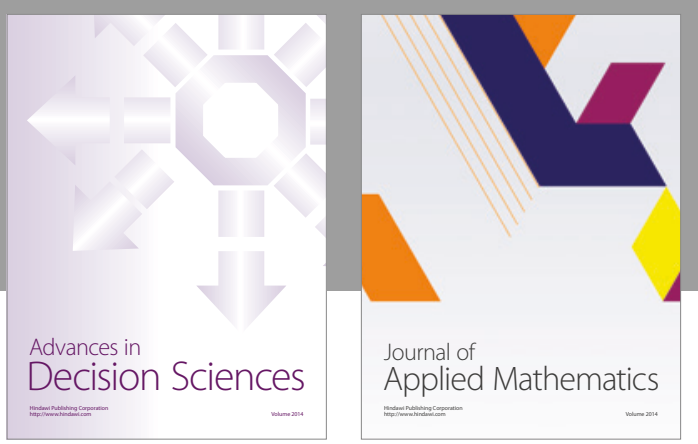

Algebra

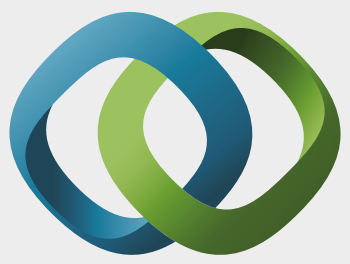

\section{Hindawi}

Submit your manuscripts at

https://www.hindawi.com
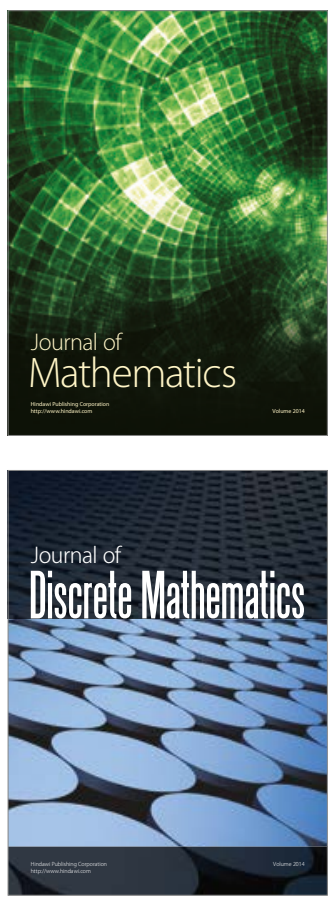

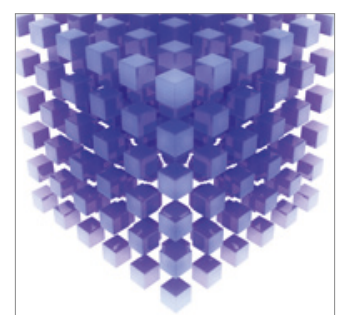

Mathematical Problems in Engineering
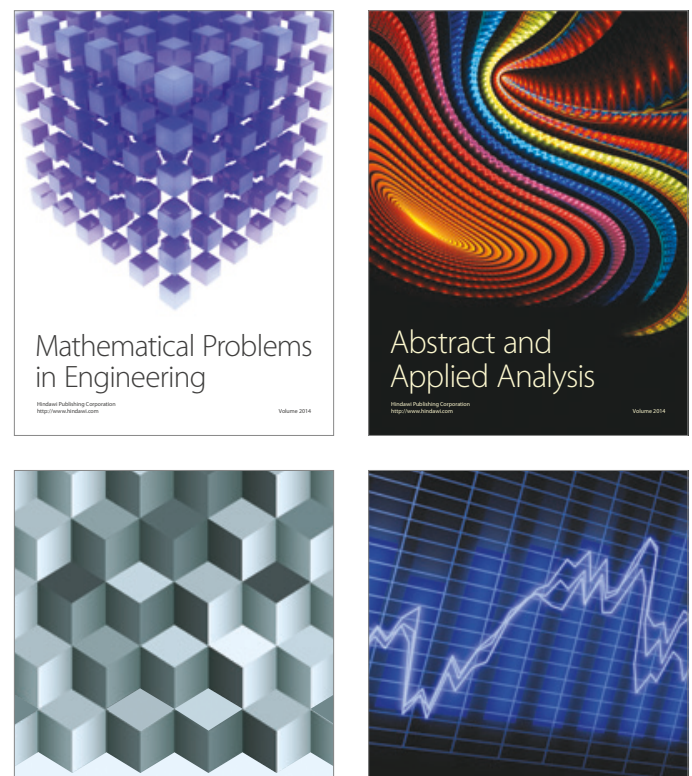

Journal of

Function Spaces

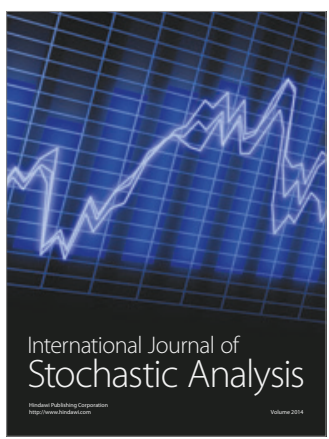

Probability and Statistics
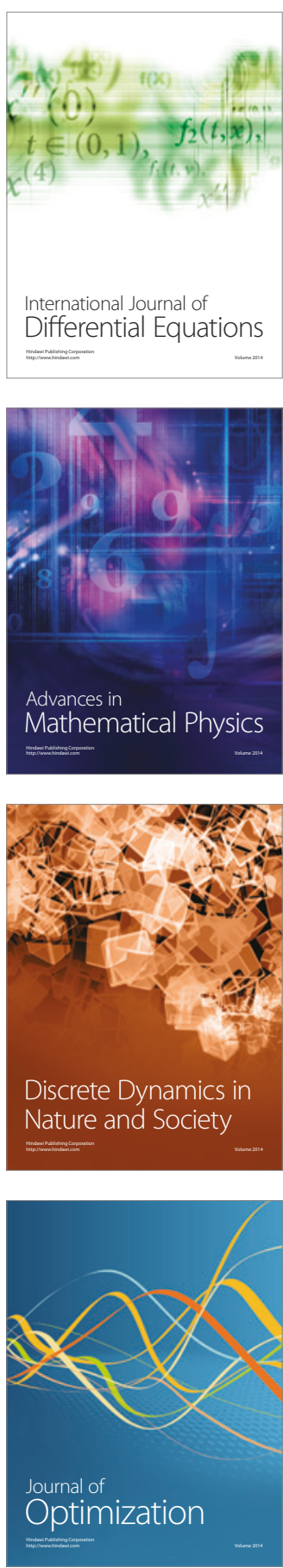